\title{
Short Communication: Correlation and regression among rice panicle branches traits
}

\author{
TRI HASTINI ${ }^{1}$, WILLY BAYUARDI SUWARNO ${ }^{2}$, MUNIF GHULAMAHDI ${ }^{2}$, HAJRIAL ASWIDINNOOR ${ }^{2, \bullet}$ \\ ${ }^{1}$ Plant Breeding and Biotechnology, Graduate School, Institut Pertanian Bogor. Jl. Raya Dramaga, IPB Dramaga Campus, Bogor 16680, West Java, \\ Indonesia. \\ ${ }^{2}$ Departement of Agronomy and Horticulture, Faculty of Agriculture, Institut Pertanian Bogor. Jl. Raya Dramaga, IPB Dramaga Campus, Bogor 16680, \\ West Java, Indonesia. Tel./fax.: +62-251-8629353, `email: hajrial@apps.ipb.ac.id, trihastini@gmail.com
}

Manuscript received: 6 March 2019. Revision accepted: 26 March 2019.

\begin{abstract}
Hastini T, Suwarno WB, Ghulamahdi M, Aswidinnoor H. 2019. Short Communication: Correlation and regression among rice panicle branches traits. Biodiversitas 20: 1140-1146. Panicle was a very important organ in rice since the grains are developed from the panicle branches. This study aimed to find out the information about the relationship among rice panicle branching traits using correlation and regression analysis. The trial was conducted at the IPB Research Station, Babakan, Bogor, Indonesia from December 2015 until April 2016. Twenty genotypes of lowland rice were used as treatments with three replications and arranged in a completely randomized design. The panicle branches traits were observed. The result showed that there was positively and a highly significant relationship among the panicle branches traits in general. Analysis using linear regression revealed that, in general, the total grains number per panicle showed the linear relationships with other traits, and only total grains number per panicle vs tertiary branches number, total grains number per panicle vs grains number of tertiary panicle branch, and total grains number per panicle vs the number of secondary branches per panicle branch showed the quadratic relationship. Among all rice panicle branching traits, the secondary panicle branches number had the highest contribution to the total grains number per panicle.
\end{abstract}

Keywords: correlation, regression, rice panicle branches

\section{INTRODUCTION}

The panicle is a very important organ in rice because from this organ the grains develop. Branching pattern in rice panicle is initiated from the development of shoot apical meristem (SAM) during the transition from vegetative to generative phase (Komatsu et al. 2001; Wang and Li 2011; Hussien et al. 2014). Wang and Li (2011) reported that primary and secondary rice branches developed from the periphery of SAM and further determined the number of branches and grains. In brief, panicle formation developes through two integrated processes, namely the formation of panicle branches and the formation of grains. Axilar meristem growth from the panicle axis formed primary branches primordial. After the development of primary branches primordial is completed, the apical meristem grows and differentiates to become the primordial of secondary branches. The differentiation of panicle stopped when the grain development in primary and secondary branches meristem is completed (Bai et al. 2016).

Rice panicle consisted of the main axis, from which the primary branches grow, followed bu the growth of secondary, and sometimes tertiary, branches. Tripathi et al. (2011) stated that the variation in the number of grains per panicle was determined by the number of panicle secondary branches. Based on the result of multiple regression analysis, the panicle branching greatly determined the number of grains per panicle. Further, the panicle architecture could be characterized based on three dimensions, i.e., (i) panicle length, primary branch length, and secondary branch length; (ii) number of primary branches and the number of secondary branches; (iii) number of grains per primary branch, number of grains per secondary branch and number of grains per panicle (Bai et al. 2016).

Correlation and regression analysis were the common techniques used to elucidate the relationship between two quantitative variables. How strong the relationship between two quantitative characters could be analyzed using correlation, while regression analysis gave the information about the direction and causal-effect relationship in the equation form (Bewick et al. 2003; Kozak et al. 2012). The common issues in the correlation relationship of the rice agronomical characters were grain yield, plant height, number of tillers per plant, panicle length, number of grains per panicle, 1000-grains weight, and number of filled grains per panicle. Number of grains per panicle usually had a positive correlation with the panicle length, and number of filled grain per panicle (Hairmansis et al. 2010; Mohamed et al. 2012; Kajonphol et al. 2018).

As many studies had shown that the grain yield showed a positive and significant correlation with the number of grains per panicle, then the number of grains per panicle could be used as the dependent variable in a regression with other traits. This study aimed to understand the correlation and regression relationship between the number of grains per panicle with other traits of rice panicle branching. The other traits would be used as a predictor in the regression analysis. Furthermore, this study could give 
the information on the panicle branching traits contribution to the total grains number per panicle.

\section{MATERIALS AND METHODS}

The trial was conducted at the IPB Research Station, Babakan, Bogor, Indonesia from December 2015 until April 2016. Twenty genotypes of lowland rice were used as treatments with three replications and arranged in completely randomized design. The twenty genotypes were IPB161-F-6-1-1, IPB160-F-82-2-1, IPB175-F-2-2-1, IPB160-F-28-3-1， IPB160-F-54-22-1， IPB160-F-3-3-1, IPB160-F-36-1-1, IPB160-F-54-5-1, IPB160-F-95-1-1, IPB160-F-7-1-1, IPB160-F-22-2-1, IPB175-F-6-1-1, IPB160-F-54-4-1， IPB175-F-13-2-1， IPB160-F-21-1-1, IPB160-F-75-2-1， IPB175-F-1-1-1， IPB160-F-47-1-1, IPB160-F-110-1-1, and Mekongga.

Each genotype was transplanted in the $1 \times 22 \mathrm{~m}^{2}$ plot in the rice field at 14 days after sowing. The planting space was $10 \times 20 \mathrm{~cm}^{2}$ with one seedling per planting hole. The standard management practices of rice cultivation were used in this study. The traits observed were panicle length (PL), which was measured from the panicle neck to the tip of panicle, total grains number per panicle (TGN), primary panicle branches number $(\mathrm{PBN})$, secondary panicle branches number (SBN), tertiary panicle branches number $(\mathrm{TBN})$, primary panicle branch length (PBL), secondary panicle branch length (SBL), grains number per primary branch, including the grains in the secondary and tertiary branches in the corresponding primary branch (GN per $\mathrm{PB}$ ), grains number per secondary branch, including the grains in the tertiary branches in the corresponding secondary branch (GN per SB), grains number of tertiary panicle branch (GNTB), total length of primary panicle branches, which was the sum of the length of primary panicle branches per panicle (TLPB), total length of secondary panicle branches, which was the sum of the length of secondary panicle branches per panicle (TLSB), the number of secondary branches per panicle branch (SB per $\mathrm{PB}$ ), percentage of grains number of tertiary panicle branches in the panicle (\% TrGN), total grains of secondary panicle branches (TGSB), and percentage of grains number of secondary panicle branches in the panicle (\%TGSB). The traits of the panicle rice branches were presented in Figure 1.

Data were collected from five randomly panicles taken from three randomly hills of each genotype and replication. The observation was done manually to all traits. The averages of the collected data were used for statistical analysis. The data taken from five panicles were averaged to obtain an average per hill. Hereafter, the data taken from three hills were averaged to obtain the average of the replication. The average of three replications was the genotype data. Data were analyzed for the correlation among all traits observed using Pearson's correlation. Furthermore, in the regression analysis, total grains number per panicle (TGN) was used as dependent variable and the other traits were used as predictors (independent variable), those each in a separate analysis. In the regression analysis, was used the average of replications data and the average of genotypes data. All statistical analysis was done using statistical software Minitab 16 and Microsoft Excel 2013.

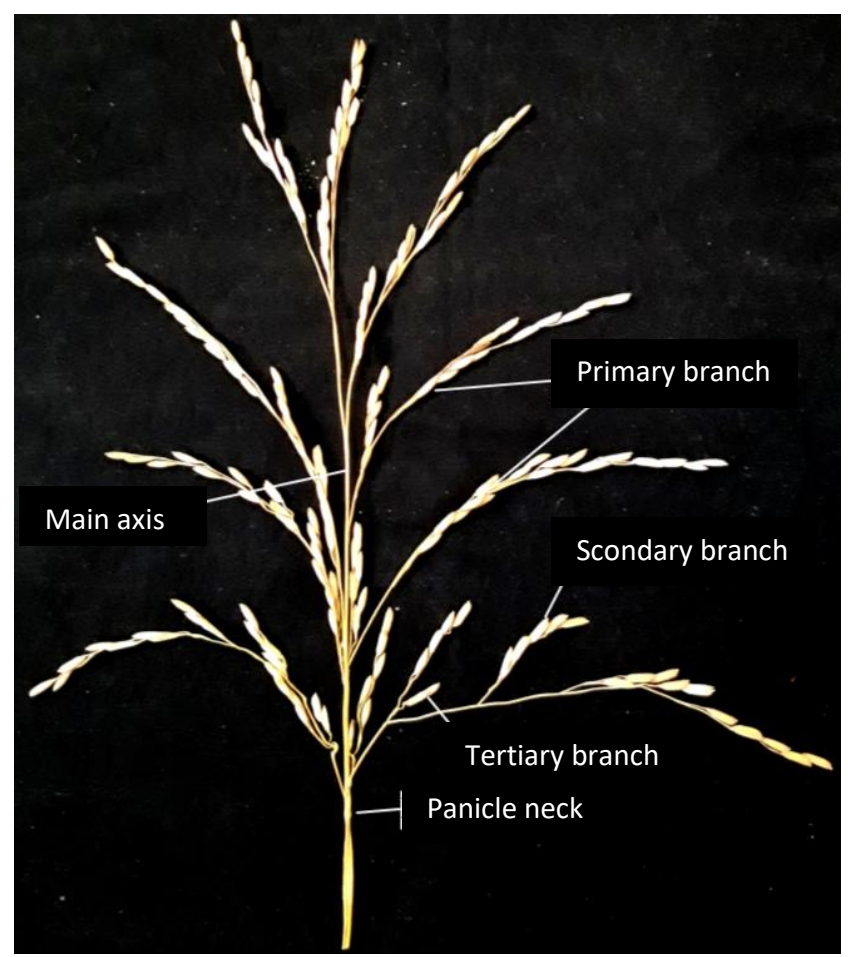

Figure 1. The complete structure of rice panicle branching. Not all genotypes possessed tertiary panicle branches.

\section{RESULTS AND DISCUSSION}

Generally, all traits showed a highly significant and positive correlation (Table 1). The correlation was not significant in the relationship between PBN vs SBL, PBN vs GN per $\mathrm{PB}, \mathrm{PBN}$ vs GN per $\mathrm{SB}, \mathrm{PBN}$ vs $\mathrm{SB}$ per $\mathrm{PB}$ and PBN vs \%TGSB. Even, the relationship between the PBN vs SBL and PBN vs GN per SB showed a negative correlation. This result was in line with that reported by Sun et al. (2017), where all populations being studied showed the striking positive correlations among the panicle length, grains number per panicle, primary panicle branch, and secondary panicle branch, but there was still no report about the other panicle branching traits. Bagheri et al. (2011) and Norain et al. (2014) reinforced the statement that there was a high significant and positive correlation between the number of grains per panicle and panicle length.

Karim et al. (2014) reported that the number of primary panicle branches per panicle had a highly significant and positive correlation with the number of filled grains per panicle. In this study, we did not use the filled grains number per panicle as the main traits because too many environmental factors influenced the trait. Thus, the total number of grains per panicle was used as the main trait as it is expected to reflect the potential yield of tested rice genotypes. In line with this expectation, Devi et al. (2016) found that the relationship between the number of grains 
per panicle and the grain yield per plant was positively and highly significantly correlated. In the other case, the filled grains per panicle indicated positive and highly significant indirect correlation with the yield per ha in phenotypic and genotypic level (Oladosu et al. (2018).

Based on the results of correlation analysis, the multiple regression analysis could not be implemented because there was a significant relationship among independent variables (multicollinearity). The multicollinearity would decrease the model goodness of fit (Zhang et al. 2018). The regression used was a linear regression. Based on the regression analysis, there was two types of relationship between TGN with other panicle branching traits. The first one was a linear relationship and the second was a quadratic one. The determination of linear or quadratic was taken from the significant equation at the highest level (Table 2). When used the averages of replication data, the linear relationship type were more than those the quadratic one (Figure 2). The linear equation showed at the relationship between TGN vs PL, PBN, SBN, PBL, SBL, GN per PB, GN per SB, TLPB, TLSB, \% TrGN, TGSB and \%TGSB. The robust linear relationship found at the TGN vs SBN, TLSB, and TGSB, characterized by the distribution of points that were close to the regression line. Besides, they had a high $\mathrm{R}^{2}$ value.

The quadratic relationship was found in the regression between TGN vs TBN, TGN vs GNTB, and TGN vs SB per PB. Based on the statistical analysis, these TBN and GNTB traits had a broad variation. The coefficient of variation $(\mathrm{CV})$ was $88.09 \%$ and $95.63 \%$ and for TBN and GNTB respectively. The large of $\mathrm{CV}$ in the TBN caused by the large irregularity in the number of tertiary panicle branches among genotypes, even among panicles in the same hills and the same genotype. Not all genotypes showed the consistently in the number of tertiary panicle branches, even there were panicles without tertiary panicle branch. As a result, the CV of GNTB also had a great value. These two traits showed the same pattern of was quadratic curve. A large $\mathrm{CV}$ of TBN was also reported by Rahayu et al. (2018). In the SB per PB, there was one genotype showing a large number of secondary branches on that primary branch (4.35 SB per $\mathrm{PB}$ ), while the average of all genotypes was $3.45 \mathrm{SB}$ per $\mathrm{PB}$, and the coefficient variation was $7.26 \%$. The variation in this case due to the replication and genotypes as the source of variation.

In the analysis using the average of hills data, showed a higher $\mathrm{CV}$ at all traits (analysis result was not presented). In this case, the source of variation were the hills, replications and genotypes. This data resulted linear dan quadratic, even cubic regression equation. The linear equation showed at the relationship between TGN vs PL, PBN, SBN, SBL, GN per PB, TLPB, TLSB, and SB per $P B$. While the quadratic equation found in the relationship between TGN vs TBN, PBL, GN per SB, GNTB\%TrGN, and TGSB. The cubic equation found in the relationship between TGN vs \%TGSB with the 0.005 p-value.

Interestingly, when used the averages of genotype data, all the traits showed the linear relationship equation (Figure 3). The equation of regression using the averages of genotypes was presented in Table 3. In this case, the hills and replications no longer as a source of variation. With this phenomenon, we guessed that the CV did not affect to the regression model, but the number of data points and its distributions did. The data points in the average of hills > average of replications $>$ average of genotypes.

Table 1. Correlations among panicle branching traits using the averages of replications

\begin{tabular}{|c|c|c|c|c|c|c|c|c|c|c|c|c|c|c|}
\hline & PL & TGN & PBN & SBN & TBN & PBL & SBL & $\begin{array}{c}\text { GN per } \\
\text { PB }\end{array}$ & $\begin{array}{c}\text { GN } \\
\text { per SB }\end{array}$ & GNTB & TLPB & TLSB & $\begin{array}{c}\text { SB per } \\
\text { PB }\end{array}$ & $\begin{array}{cc}\% & \text { TGSB } \\
\text { TrGN }\end{array}$ \\
\hline TGN & $0.634^{* * *}$ & & & & & & & & & & & & & \\
\hline PBN & $0.411^{* *}$ & $0.644 * *$ & & & & & & & & & & & & \\
\hline SBN & $0.540^{* *}$ & $0.946^{* *}$ & $0.696^{* *}$ & & & & & & & & & & & \\
\hline TBN & $0.480^{* *}$ & $0.790^{* *}$ & $0.366^{* *}$ & $0.727 * *$ & & & & & & & & & & \\
\hline PBL & $0.889^{* *}$ & $0.594 * *$ & $0.284^{*}$ & $0.501 * *$ & $0.475^{* *}$ & & & & & & & & & \\
\hline SBL & $0.682^{* *}$ & $0.440 * *$ & $-0.008 \mathrm{~ns}$ & $0.306^{*}$ & $0.404^{* *}$ & $0.763^{* *}$ & & & & & & & & \\
\hline GN per $\mathrm{PB}$ & $0.514^{* *}$ & $0.761^{* *}$ & $0.015 \mathrm{~ns}$ & $0.671^{* *}$ & $0.692^{* *}$ & $0.581^{* *}$ & $0.635^{* *}$ & & & & & & & \\
\hline GN per SB & $0.454^{* *}$ & $0.558^{* *}$ & $-0.111 \mathrm{~ns}$ & $0.371^{* *}$ & $0.533^{* *}$ & $0.585^{* *}$ & $0.768^{* *}$ & $0.840 * *$ & & & & & & \\
\hline GNTB & $0.491^{* *}$ & $0.780^{* *}$ & $0.353^{* *}$ & $0.712 * *$ & $0.999 * *$ & $0482 * *$ & $0.421^{* *}$ & $0.690 * *$ & $0.536 * *$ & & & & & \\
\hline TLPB & $0.811^{* *}$ & $0.787 * *$ & $0.806^{* *}$ & $0.757 * *$ & $0.550 * *$ & $0.786^{* *}$ & $0.478^{* *}$ & $0.384 * *$ & $0.304^{*}$ & $0.547^{* *}$ & & & & \\
\hline TLSB & $0.709^{* *}$ & $0.939 * *$ & $0.552 * *$ & $0.927 * *$ & $0.784 * *$ & $0.701 * *$ & $0.630^{* * *}$ & $0.793 * *$ & $0.588 * *$ & $0.781 * *$ & $0.796^{* *}$ & & & \\
\hline SB per $\mathrm{PB}$ & $0.460^{* *}$ & 0.800 ** & $0.190 \mathrm{~ns}$ & $0.829 * *$ & $0.692 * *$ & $0.501^{* *}$ & $0.460^{* * *}$ & $0.914 * *$ & $0.607 * *$ & $0.683^{* *}$ & $0.442 * *$ & $0.850 * *$ & & \\
\hline$\%$ TrGN & $0.452^{* *}$ & $0.777 * *$ & $0.299^{*}$ & $0.711 * *$ & $0.986^{* *}$ & $0.476^{* *}$ & $0.444 * *$ & $0.741 * *$ & $0.599 * *$ & $0.983^{* *}$ & 0.510 ** & $0.781 * *$ & $0.730^{* *}$ & \\
\hline TGSB & $0.573^{* *}$ & $0.983^{* *}$ & $0.550 * *$ & $0.947 * *$ & $0.810^{* *}$ & $0.572 * *$ & $0.444 * *$ & $0.812 * *$ & $0.589 * *$ & $0.800 * *$ & $0.715^{* *}$ & $0.942 * *$ & $0.872 * *$ & $0.811^{* *}$ \\
\hline \% TGSB & $0.292^{*}$ & $0.719^{* *}$ & $0.185 \mathrm{~ns}$ & $0.754 * *$ & $0.576^{* *}$ & $0.414^{* *}$ & $0.373^{* *}$ & $0.784 * *$ & $0.562 * *$ & $0.561 * *$ & $0.381 * *$ & $0.743^{* *}$ & $0.901 * *$ & $0.628 * * 0.823 * *$ \\
\hline
\end{tabular}

Note: $\mathrm{PL}=$ panicle length; TGN = total grains number; $\mathrm{PBN}=$ primary branches number; $\mathrm{SBN}=$ secondary branches number; TBN = tertiary branches number; $\mathrm{PBL}=$ primary branch length; $\mathrm{SBL}=$ secondary branch length; $\mathrm{GN}$ per $\mathrm{PB}=$ grains number per primary branch; GN per SB = grains number per secondary branch; GNTB = grains number of tertiary branch; TLPB = total length of primary branches; TLSB = total length of secondary branches; SB per PB = number of secondary branch per primary branch; $\%$ TrGN $=$ $\%$ tertiary grains number; TGSB $=$ total grains of secondary branches; $\%$ TGSB $=\%$ total grains of secondary branches; $* *=$ significant in $0.01 \% \alpha ; *$ significant in $0.05 \% \alpha$; ns $=$ non significant. 

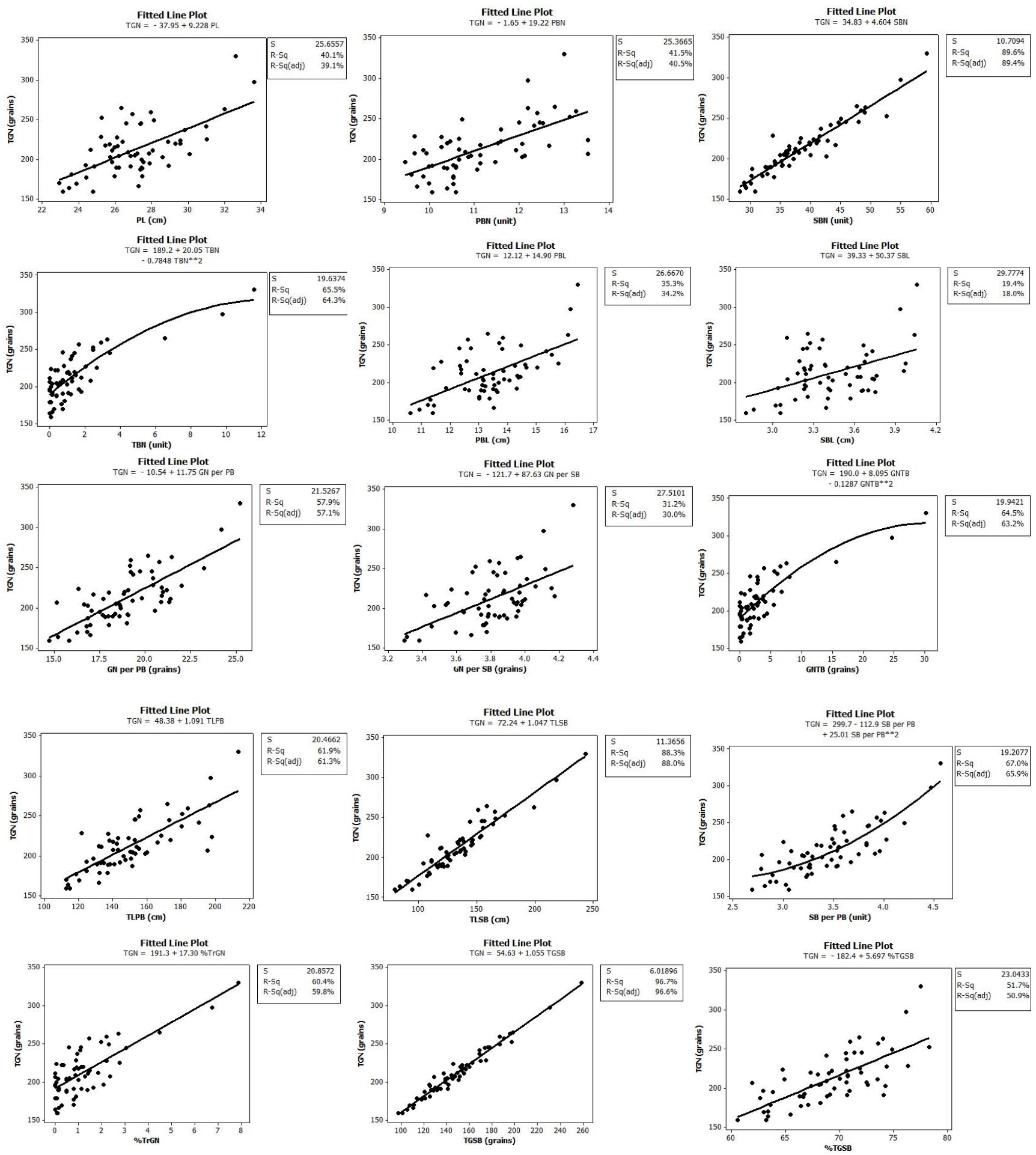

Figure 2. The fitted line plot and regression between TGN vs other traits using the averages of replications. The quadratic relationship was found in the regression between TGN vs TBN, TGN vs GNTB, and TGN vs SB per PB

The positive and significant regression means that the dependent variable would increase alon $\mathrm{g}$ with the increase of the independent variable by a particular equation. As the dependent variable, the TGN increased by the increase of PL, PBN, SBN, PBL, SBL, GN per PB, GN per SB, TLPB, TLSB, \% TrGN, TGSB, and \%TGSB in a linear fashion. On the other hand, the increase of TBN, GNTB, and CB per PB also contributed to the TGN by quadratic equation way. Secondary panicle branches showed the greatest contribution to the number of grains per panicle, through the number of secondary panicle branches, total length of secondary panicle branches and total grains of secondary panicle branches (Figure 2). Based on multiple regression analysis, found that the greatest contribution to the number of grains per panicle were the number of secondary branches (Bai et al. 2016). 

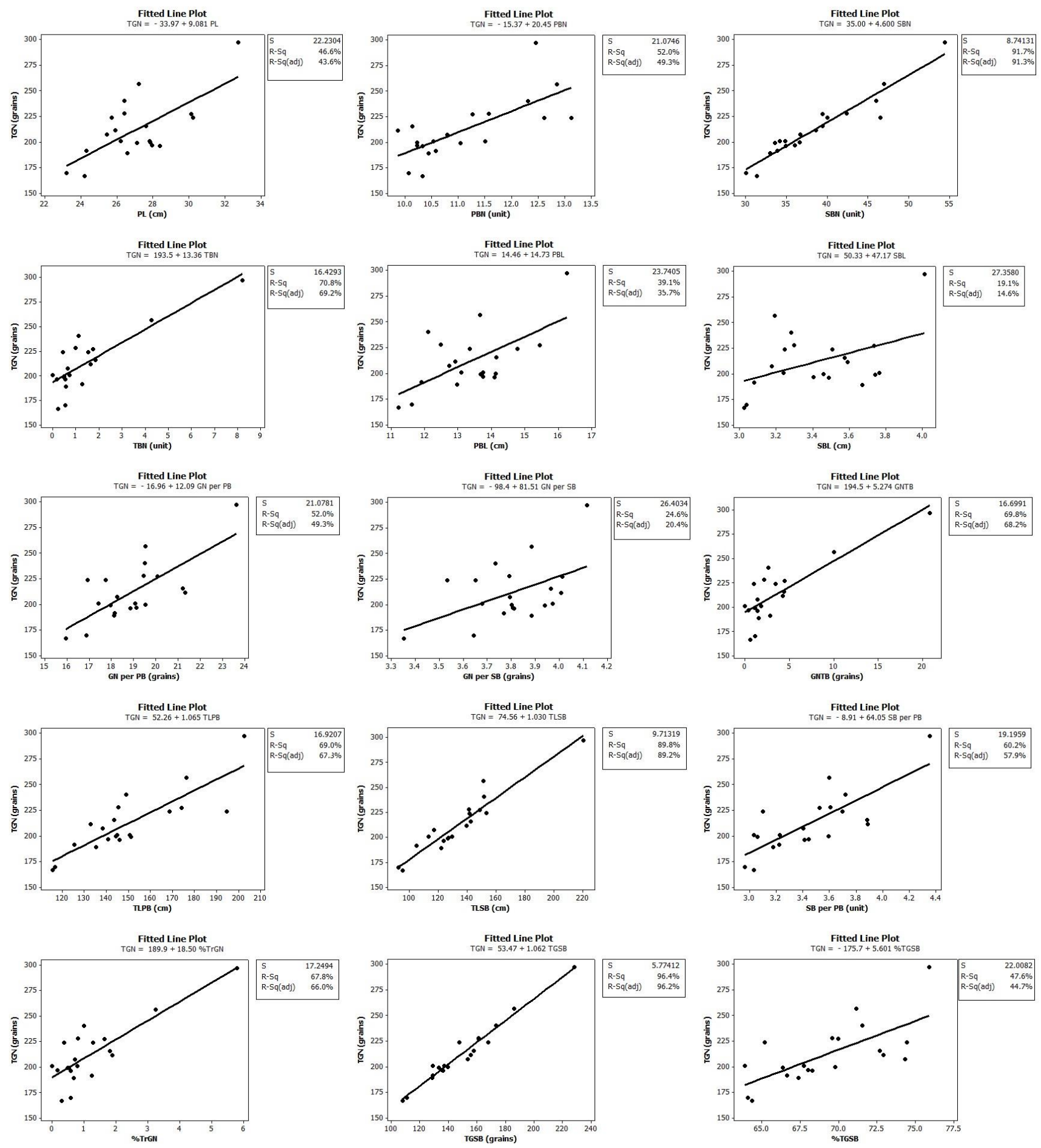

Figure 3. The fitted line plot and regression between TGN vs other traits using the averages of genotypes

Usually, $\mathrm{R}^{2}$ is used to measure the magnitude of the regression equation strength. $R^{2}$ value indicated the variability percentage of the dependent variable that was explained by the model (Sellam and Poovammal 2016). $\mathrm{R}^{2}$ or coefficient of determination gave the information on how high the dependent variable variation was due to the independent or predictor variable (Schneider et al. 2010). In this study, the lowest $\mathrm{R}^{2}$ was $19.4 \%$ showed on the regression between TGN vs SBL, and the highest was
$96.7 \%$ on the regression between TGN vs TGSB. Interestingly, this result supported the report from Bai et al. (2016) and Bagheri et al. (2011). Mohapatra (2013) stated that rice yield potential can be increased by redesigning the new plant type (NPT) of rice, where the secondary panicle branches had an important role. The spikelet of rice in NPT would increase due to a large number of spikelets that those were accommodated by the secondary panicle branches. 
Table 2. Linear and quadratic regression equation of TGN vs other traits using the averages of replications

\begin{tabular}{|c|c|c|c|c|}
\hline Traits & Linear equation & p-value & Quadratic equation & p-value \\
\hline PL & $\mathrm{TGN}=-37.5+9.228 \mathrm{PL}$ & $0.000 * *$ & TGN $=391.7-21.89 \mathrm{PL}+0.5592 \mathrm{PL}^{2}$ & $0.222 \mathrm{~ns}$ \\
\hline PBN & $\mathrm{TGN}=-1.65+19.22 \mathrm{PBN}$ & $0.000 * *$ & $\mathrm{TGN}=77.1+5.30 \mathrm{PBN}+0.609 \mathrm{PBN}^{2}$ & $0.833 \mathrm{~ns}$ \\
\hline SBN & $\mathrm{TGN}=34.83+4.604 \mathrm{SBN}$ & $0.000 * *$ & $\mathrm{TGN}=77.29+2.486 \mathrm{SBN}+0.02559 \mathrm{SBN}^{2}$ & $0.274 \mathrm{~ns}$ \\
\hline TBN & $\mathrm{TGN}=194.8+12.45 \mathrm{TBN}$ & $0.000 * *$ & $\mathrm{TGN}=189.2+20.05 \mathrm{TBN}-0.7848 \mathrm{TBN}^{2}$ & $0.025^{*}$ \\
\hline PBL & $\mathrm{TGN}=12.12+14.90 \mathrm{PBL}$ & $0.000 * *$ & $\mathrm{TGN}=496.7-57.51 \mathrm{PBL}+2.680 \mathrm{PBL}^{2}$ & $0.070 \mathrm{~ns}$ \\
\hline SBL & $\mathrm{TGN}=39.33+50.37 \mathrm{SBL}$ & $0.000 * *$ & $\mathrm{TGN}=414.5-167.6 \mathrm{SBL}+31.45 \mathrm{SBL}^{2}$ & $0.422 \mathrm{~ns}$ \\
\hline GN per $\mathrm{PB}$ & TGN $=-10.54+11.75$ GN per PB & $0.000 * *$ & $\mathrm{TGN}=266.9-17.12 \mathrm{GN}$ per $\mathrm{PB}+0.7414 \mathrm{GN}$ per $\mathrm{PB}^{2}$ & $0.081 \mathrm{~ns}$ \\
\hline GN per SB & $\mathrm{TGN}=-121.7+87.63 \mathrm{GN}$ per SB & $0.000 * *$ & $\mathrm{TGN}=1153-591.8 \mathrm{GN}$ per $\mathrm{SB}+90.23 \mathrm{GN}$ per $\mathrm{SB}^{2}$ & $0.127 \mathrm{~ns}$ \\
\hline GNTB & $\mathrm{TGN}=195.9+4.846 \mathrm{GNTB}$ & $0.000 * *$ & $\mathrm{TGN}=190.0+8.095 \mathrm{GNTB}-0.1287 \mathrm{GNTB}^{2}$ & $0.019 *$ \\
\hline TLPB & $\mathrm{TGN}=48.38+1.091 \mathrm{TLPB}$ & $0.000 * *$ & $\mathrm{TGN}=74.00+0.759 \mathrm{TLPB}+0.001053 \mathrm{TLPB}^{2}$ & $0.632 \mathrm{~ns}$ \\
\hline TLSB & $\mathrm{TGN}=72.24+1.047 \mathrm{TLSB}$ & $0.000 * *$ & $\mathrm{TGN}=70.79+1.067 \mathrm{TLSB}-0.000067 \mathrm{TLSB}^{2}$ & $0.944 n s$ \\
\hline SB per $\mathrm{PB}$ & $\mathrm{TGN}=-8.81+64.03 \mathrm{SB}$ per $\mathrm{PB}$ & $0.000 * *$ & $\mathrm{TGN}=299.7-112.9 \mathrm{SB}$ per $\mathrm{PB}+25.01 \mathrm{SB}$ per $\mathrm{PB}^{2}$ & $0.027 *$ \\
\hline$\%$ TrGN & $\mathrm{TGN}=191.3+17.30 \% \mathrm{TrGN}$ & $0.000 * *$ & $\mathrm{TGN}=190.0+19.46 \% \operatorname{TrGN}-0.3442 \% \operatorname{TrGN}^{2}$ & $0.621 \mathrm{~ns}$ \\
\hline TGSB & $\mathrm{TGN}=54.63+1.055 \mathrm{TGSB}$ & $0.000 * *$ & $\mathrm{TGN}=58.71+1.003 \mathrm{TGSB}+0.000157 \mathrm{TGSB}^{2}$ & $0.763 \mathrm{~ns}$ \\
\hline$\%$ TGSB & $\mathrm{TGN}=-182.4+5.697 \% \mathrm{TGSB}$ & $0.000 * *$ & $\mathrm{TGN}=778.0-22.15 \% \mathrm{TGSB}+0.2011 \% \mathrm{TGSB}^{2}$ & $0.178 \mathrm{~ns}$ \\
\hline
\end{tabular}

Note: $\mathrm{PL}=$ panicle length; $\mathrm{TGN}=$ total grains number; $\mathrm{PBN}=$ primary branches number; $\mathrm{SBN}=$ secondary branches number; $\mathrm{TBN}=$ tertiary branches number; $\mathrm{PBL}=$ primary branch length; $\mathrm{SBL}=$ secondary branch length; $\mathrm{GN}$ per $\mathrm{PB}=$ grains number per primary branch; GN per SB = grains number per secondary branch; GNTB = grains number of tertiary branch; TLPB = total length of primary branches; TLSB = total length of secondary branches; SB per PB = number of secondary branch per primary branch; $\%$ TrGN $=$ $\%$ tertiary grains number; TGSB $=$ total grains of secondary branches; $\%$ TGSB $=\%$ total grains of secondary branches; $* *=$ significant in $0.01 \% \alpha ; *$ significant in $0.05 \% \alpha$; ns $=$ non significant.

Table 3. Linear and quadratic regression equation of TGN vs other traits using the averages of genotypes

\begin{tabular}{|c|c|c|c|c|}
\hline Traits & Linear equation & p-value & Quadratic equation & p-value \\
\hline $\mathrm{PL}$ & TGN $=-33.97+9.081 \quad$ PL & $0.001 * *$ & TGN $=426.9-24.30 \mathrm{PL}+0.6003 \mathrm{PL}^{2}$ & $0.420 \mathrm{~ns}$ \\
\hline $\mathrm{PBN}$ & $\mathrm{TGN}=-15.37+20.45 \mathrm{PBN}$ & $0.000 * *$ & $\mathrm{TGN}=-85.7+32.8 \mathrm{PBN}-0.541 \mathrm{PBN}^{2}$ & $0.931 \mathrm{~ns}$ \\
\hline SBN & $\mathrm{TGN}=35.00+4.600 \mathrm{SBN}$ & $0.000 * *$ & $\mathrm{TGN}=71.59+2.785 \mathrm{SBN}+0.02192 \mathrm{SBN}^{2}$ & $0.638 \mathrm{~ns}$ \\
\hline TBN & $\mathrm{TGN}=193.5+13.36 \mathrm{TBN}$ & $0.000 * *$ & $\mathrm{TGN}=189.0+19.66 \mathrm{TBN}-0.8044 \mathrm{TBN}^{2}$ & $0.367 \mathrm{~ns}$ \\
\hline PBL & $\mathrm{TGN}=14.46+14.73 \mathrm{PBL}$ & $0.003 * *$ & $\mathrm{TGN}=540.6-63.18 \mathrm{PBL}+2.860 \mathrm{PBL}^{2}$ & $0.292 \mathrm{~ns}$ \\
\hline SBL & $\mathrm{TGN}=50.33+47.17 \mathrm{SBL}$ & $0.05 \mathrm{~ns}$ & $\mathrm{TGN}=884.8-437.1 \mathrm{SBL}+69.83 \mathrm{SBL}^{2}$ & $0.399 \mathrm{~ns}$ \\
\hline GN per $\mathrm{PB}$ & $\mathrm{TGN}=-16.96+12.09 \mathrm{GN}$ per $\mathrm{PB}$ & $0.000 * *$ & $\mathrm{TGN}=348.0-25.46 \mathrm{GN}$ per $\mathrm{PB}+0.957 \mathrm{GN}$ per $\mathrm{PB}^{2}$ & $0.387 \mathrm{~ns}$ \\
\hline GN per SB & $\mathrm{TGN}=-98.4+81.51 \mathrm{GN}$ per $\mathrm{SB}$ & $0.026 *$ & $\mathrm{TGN}=1572-811 \mathrm{GN}$ per $\mathrm{SB}+118.9 \mathrm{GN}$ per $\mathrm{SB}^{2}$ & $0.396 \mathrm{~ns}$ \\
\hline GNTB & $\mathrm{TGN}=194.5+5.274$ GNTB & $0.000 * *$ & $\mathrm{TGN}=189.6+8.129 \mathrm{GNTB}-0.1436 \mathrm{GNTB}^{2}$ & $0.310 \mathrm{~ns}$ \\
\hline TLPB & $\mathrm{TGN}=52.26+1.065 \mathrm{TLPB}$ & $0.000 * *$ & $\mathrm{TGN}=46.6+1.139 \mathrm{TLPB}-0.000232 \mathrm{TLPB}^{2}$ & $0.971 \mathrm{~ns}$ \\
\hline TLSB & $\mathrm{TGN}=74.56+1.030 \mathrm{TLSB}$ & $0.000 * *$ & $\mathrm{TGN}=57.98+1.258 \mathrm{TLSB}-0.000752 \mathrm{TLSB}^{2}$ & $0.644 \mathrm{~ns}$ \\
\hline SB per PB & $\mathrm{TGN}=-8.91+64.05 \mathrm{SB}$ per $\mathrm{PB}$ & $0.000 * *$ & $\mathrm{TGN}=372.0-152.0 \mathrm{SB}$ per $\mathrm{PB}+30.31 \mathrm{SB}$ per $\mathrm{PB}^{2}$ & $0.281 \mathrm{~ns}$ \\
\hline$\%$ TrGN & $\mathrm{TGN}=189.9+18.50 \% \operatorname{TrGN}$ & $0.000 * *$ & $\mathrm{TGN}=190.4+17.68 \% \operatorname{TrGN}+0.151 \% \operatorname{TrGN}^{2}$ & $0.931 \mathrm{~ns}$ \\
\hline TGSB & $\mathrm{TGN}=53.47+1.062 \mathrm{TGSB}$ & $0.000 * *$ & $\mathrm{TGN}=60.63+0.9719 \mathrm{TGSB}+0.000276 \mathrm{TGSB}^{2}$ & $0.818 \mathrm{~ns}$ \\
\hline$\%$ TGSB & $\mathrm{TGN}=-175.7+5.601 \% \mathrm{TGSB}$ & $0.001 * *$ & $\mathrm{TGN}=971-27.46 \% \mathrm{TGSB}+0.2376 \% \mathrm{TGSB}^{2}$ & $0.568 \mathrm{~ns}$ \\
\hline
\end{tabular}

Note: $\mathrm{PL}=$ panicle length; $\mathrm{TGN}=$ total grains number; $\mathrm{PBN}=$ primary branches number; $\mathrm{SBN}=$ secondary branches number; $\mathrm{TBN}=$ tertiary branches number; $\mathrm{PBL}=$ primary branch length; $\mathrm{SBL}=$ secondary branch length; $\mathrm{GN}$ per $\mathrm{PB}=$ grains number per primary branch; GN per SB = grains number per secondary branch; GNTB = grains number of tertiary branch; TLPB = total length of primary branches; TLSB = total length of secondary branches; SB per PB = number of secondary branch per primary branch; \% TrGN = $\%$ tertiary grains number; TGSB $=$ total grains of secondary branches; $\%$ TGSB $=\%$ total grains of secondary branches; $* *=$ significant in $0.01 \% \alpha ; *$ significant in $0.05 \% \alpha$; ns = non significant.

As a key factor to determine the yield, the architecture of rice panicle branching was interesting to be studied. The rice panicle branching traits had a broad variation among genotypes, and those traits showed positively and highly significant correlation. The equation model of regression was affected by the the number of data points and its distributions. Further analysis to average of replication data using regression gave the information that in general, the regression between TGN vs other traits showed the linear relationship, and only TGN vs TBN, TGN vs GNTB, and TGN vs SB per PB showed the quadratic relationship. Among all rice panicle branching traits, the SBN had the highest contribution to the TGN. 


\section{ACKNOWLEDGEMENTS}

This study was supported by Ministry of Research, Technology and Higher Education of the Republic of Indonesia, contract no 079/SP2H/LT/DRPM/II/2016 to H.A. Scholarship for Tri Hastini was provided by Ministry of Agriculture, Republic of Indonesia

\section{REFERENCES}

Bagheri N, Babaelan-Jelodar N, Pasha A. 2011. Path coefficient analysis for yield and yield components in diverse rice (Oryza sativa L.) genotypes. Biharean Biol 5 (1): 32-35.

Bai X, Zhao H, Huang Y, Xia W, Han Z, Zhang B, Guo Z, Yang L, Dong $\mathrm{H}$, Xue $\mathrm{W}$ et al. 2016. Genome-wide association analysis reveals different genetic control in panicle architecture between indica and japonica rice. The Plant Genome 9 (2): 1-10.

Bewick V, Cheek L, Ball J. 2003. Statistic review 7: correlation and regression. Critical Care (7): 451-459.

Devi KR, Parimala K, Srinivas G, Cheralu C. 2016. Variability and association of yield components and quality traits in upland rice (Oryza sativa L.). Environ Ecol 34 (4C): 2306-2310.

Hairmansis A, Kustianto B, Supartopo, Suwarno. 2010. Correlation analysis of agronomic characters and grain yield of rice for tidal swamp areas. Indonesian J Agric Sci 11 (1): 11-15.

Hussien A, Tavakol E, Horner DS, Munoz-Amatriain M, Muehlbauer GJ, Rossini L. 2014. Genetics of tillering in rice and barley. The Plant Genome 7 (1): 1-20.

Kajonphol T, Seetaput N, Precharattana, Sangsiri C. 2018. Correlation and multiple regression model for economic traits of local rice (Oryza sativa L.) in upland rice system. Appl Mechan Mater 879: 71-77.

Karim D, Siddique MNA, Sarkar U, hasnat MZ, Sultana J. 2014. Phenotypic and genotypic correlation co-efficient of quantitative characters and character association of aromatic rice. J Biosci Agric Res 1 (1): 34-46.

Komatsu M, Maekawa M, Shimamoto K, Kyozuka J. 2001. The Lax1 and Frizzy panicle 2 genes determine the inflorescence architecture of rice by controlling rachis-branch and spikelet development. Dev Biol 231: 363-373.
Kozak M, Krzanowski W, Tartanus M. 2012. Use of the coefficient in agricultural sciences: problems, pitfalls and how to deal with them. Ann Acad Bras Cienc 84 (4): 1147-1156.

Mohamed KA, Idris AE, Mohammed HI, Adam KA. 2012. Ranking rice (Oryza sativa L.) genotypes using multi-criteria decision making, correlation and path coefficient analysis. British Biotechnol J 2 (4) : 211-228.

Mohapatra PK. 2013. A physiological approach to design rice panicle architecture in the quest for high grains yield. International Dialogue on Perception and Prospects of Designer Rice. Hyderabad Directorate of Rice Research- Society for Advancement of Rice Research, India.

Norain MN, Shamsiah A, Abdul RH, Nor AH, Haslinda AM, Wan AWA. 2014. Correlation analysis on agronomic characters in F2 population derived from MR64 and Pongsu Seribu 2. J Appl Sci Agric 9 (18): 143-147.

Oladosu Y, Rafii MY, Magaji U, Abdullah N, Miah G, Chukwu SC, Hussin G, Ramli A, Kareem I. 2018. Genotypic and phenotypic relationship among yield components in rice under tropical conditions. Biomed Res Int. 2018: 8936767. DOI: 10.1155/2018/8936767.

Rahayu S, Suwarno WB, Ghulamahdi M, Aswidinnoor H. 2018. Analysis of panicle morphology traits in F2 and reciprocal F2 populations of rice (Oryza sativa L.). SABRAO J Breed Genet 50 (1): 9-24.

Schneider A, Hommel G, Blettner M. 2010. Linear regression analysispart 14 of a series on evaluation of scientific publications. Dtsch Arztebl Intl 107 (44): 776-782.

Sellam V, Poovammal E. 2016. Prediction of crop yield using regression analysis. Indian J Sci Technol 9 (38): 1-5.

Sun Z, Yin X, Ding J, Yu D, Hu M, Sun X, Tan Y, Sheng X, Liu L, Mo Y, Ouyang N, Jiang B, Yuan G, Duan M, Yuan D, Fang J. 2017. QTL analysis and dissection of panicle components in rice using advanced backcross populations derived from Oryza sativa cultivars HR1128 and 'Nipponbare'. PLoS One 12 (4): e0175692. DOI: 10.1371/journal.pone.0175692.

Tripathi KK, Govila OP, Warrier R, Ahuja V. 2011. Biology of Oryza sativa L. (Rice). Department of Biotechnology, Ministry of Science and Technology and Ministry of Environment and Forest. Govt. of India, New Delhi.

Wang Y, Li J. 2011. Branching in rice. Curr Opin Plant Biol 14: 94-99.

Zhang X, Zhao C, Wang H, Zhang F, Zhao J, Wu G. 2018. A regression equation model for height and weight prediction. J Phys Conf Ser 1087: 1-7. 